\title{
População microbiana em solo cultivado com soja e tratado com diferentes herbicidas em área de cerrado no estado de Roraima
}

\author{
Jerri Édson ZILLI ${ }^{1}$, Oscar José SMIDERLE ${ }^{1}$ Maria Cristina Prata NEVES², Norma Gouvêa RUMJANEK
}

\begin{abstract}
RESUMO
Este trabalho objetivou avaliar o impacto de herbicidas à base de glyphosate, imazaquin e trifluralin na biomassa microbiana do solo, na comunidade bacteriana associada ao rizoplano de soja e também na nodulação das plantas de soja. As avaliações foram realizadas por um período de 60 dias, em dois sistemas de manejo do solo: semeadura direta na palha (SD) e semeadura convencional (SC), que receberam a aplicação dos herbicidas glyphosate e, imazaquin e trifluralin, respectivamente. Ao longo do período estudado o imazaquin, na área de SD, ocasionou redução da biomassa microbiana e, também alterou o perfil bacteriano analisado por eletroforese em gel com gradiente desnaturante (DGGE) de forma mais intensa, que o glyphosate. Na área de SC não houve efeito significativo dos herbicidas sobre a biomassa microbiana, tendo ocorrido grande variabilidade entre repetições de um mesmo tratamento nos perfis de DGGE, o que dificultou a observação do efeito dos herbicidas. O seqüenciamento de fragmentos do 16S rDNA retirados dos géis de DGGE mostrou que o glyphosate restringiu o desenvolvimento de uma bactéria com $90 \%$ de homologia com Herbaspirillum sp., enquanto, o imazaquin estimulou uma bactéria com $96 \%$ de homologia com Ralstonia sp. e, outras bactérias com pelo menos 92\% de homologia com Burkholderia, Thiomonas e Pseudomonas não foram afetadas. Também não houve efeito dos herbicidas sobre o número de nódulos nas plantas de soja.
\end{abstract}

PALAVRAS-CHAVE

Biomassa Microbiana, glyphosate, imazaquin, trifluralin, DGGE.

\section{Microbial population in soil cultivated with soybean and treated with different berbicides in cerrado area of Roraima}

\begin{abstract}
This work aimed to evaluate the impact of glyphosate, imazaquin and trifluralin on soil microbial biomass, on bacteria community associated with soybean rhizoplane and soybean nodulation under two different agricultural management: no-tillage (SD) and conventional tillage (SC). The results showed that imazaquin in SD area lead a significant reduction of soil microbial biomass during the period of evaluation ( 60 days) and, also had greater modifications in bacterial DGGE profile than the glyphosate treatment. There was no significant effect of herbicides on microbial biomass in SC area, and DGGE profiles presented high variability among replicates of the same treatments, which had difficult the observation of herbicides effects. Some fragments excised from DGGE gels and sequenced indicate that glyphosate interfered in the development of a bacterium with 90\% of homology to Herbaspirillum sp. 16S rDNA, while another with $96 \%$ of homology to Ralstonia $s p .16 \mathrm{~S} r D N A$ was greatly present only in imazaquin treatment, and some others bacteria with more than 92\% of homology like Burkholderia, Thiomonas and Pseudomonas were not affected by herbicides. Besides that, no significant effect of the herbicides occurred on soybean nodulation.
\end{abstract}

KEYWORDS

Microbial biomass, glyphosate, imazaquin, trifluralin, DGGE.

1Embrapa Roraima-BR 174 Km 8, Distrito Industrial, Cep 69301-970, CP 133, Boa Vista RR. e-mail: zilli@cpafrr.embrapa.br; ojsmider@cpafrr.embrapa.br

2Embrapa Agrobiologia-BR 465 Km 7, Bairro Ecologia, Cep 23890-000, CP 74505, Seropédica RJ. e-mail: mcpneves@cnpab.embrapa.br; norma@cnpab.embrapa.br 


\section{INTRODUÇÃO}

Os cerrados da Amazônia Setentrional brasileira, em Roraima, conhecidos também como Lavrados, apresentam fertilidade do solo naturalmente muito baixa e sazonalidade pluviométrica. Cerca de $80 \%$ dos $1600 \mathrm{~mm}$ anuais de chuva ocorrem entre abril e agosto (Gianluppi, 1997). Essas condições edafoclimáticas propiciam baixo acúmulo de matéria orgânica no solo, refletindo em reduzida capacidade de retenção de água e nutrientes, o que caracteriza o Lavrado como um ecossistema frágil (Luizão \& Luizão, 1997).

Mesmo sob estas condiçôes, tem sido identificado promissor potencial agrícola para a região. Isto, devido à topografia suavemente ondulada, com cobertura vegetal graminácea e pequena ocorrência de arbustos, o que facilita a mecanização. Além disso, observa-se nesta região alta insolação pela proximidade da linha do Equador, o que se reflete em qualidade dos grãos produzidos e a época de colheita na entressafra do Centro-Sul, possibilitando obter preços mais competitivos.

De acordo com estudo conduzido pelo Banco Nacional de Desenvolvimento Econômico e Social (BNDS) e Embrapa, há disponibilidade de pelo menos 1,2 milhôes de hectares aptos à produção vegetal em área de cerrado (Gianluppi \& Smiderle, 2003). O destaque da agricultura em Roraima tem sido tão importante a ponto de atrair agricultores de outras regiôes do país, que vêm realizando crescentes investimentos na região. Durante a última década, o Estado de Roraima tem apresentado importante desenvolvimento agrícola, especialmente para as lavouras de soja, milho e arroz.

Entretanto, apesar deste cenário otimista, há uma série de preocupaçōes sobre o desenvolvimento agrícola regional, decorrente principalmente da susceptibilidade deste ecossistema às açôes antrópicas. Isto tem servido de alerta para a necessidade de monitorar os cultivos e fornecer alternativas viáveis para a agricultura nos cerrados, preservando os igarapés e incentivando a utilização do plantio direto (Gianluppi \& Smiderle, 2003, Gianluppi et al., 2004).

Outra preocupação importante quanto à conservação dos recursos biológicos é a necessidade de racionalizar a utilização de fertilizantes e agrotóxicos na implantação e condução das lavouras (Gianluppi et al., 2000; 2004). Isto porque, o plantio das lavouras coincide com a estação chuvosa, existindo o risco de insumos estarem sendo transportados para os mananciais de água e percolados no perfil do solo, afetando organismos não-alvos.

O impacto do uso de agrotóxicos, especialmente sobre os microrganismos do solo, também merece atenção, uma vez que os microrganismos desempenham papel preponderante na ciclagem de nutrientes e estabilização da matéria orgânica do solo (Feigl et al., 1998). Além disso, atuam nos processos de sucessão ecológica, através de relações de antagonismo e/ou sinergismo que resulta no equilíbrio dinâmico da população microbiana (Kennedy, 1999; Pereira et al., 1999).

Em ambientes onde há baixa reposição de resíduos vegetais e, baixa disponibilidade de nutrientes, a importância dos microrganismos é destacada, pois há a necessidade de ciclagem dos nutrientes que estão retidos principalmente na serrapilheira (Villela, 1997). É sabido que vários nutrientes, incluindo nitrogênio e fósforo são freqüentemente limitantes do desenvolvimento vegetal nesse ecossistema (Luizão \& Luizão, 1997), o que dá uma dimensão da alta dependência desse ambiente aos processos microbiológicos como, por exemplo a fixação biológica de nitrogênio e a solubilização de fosfatos. Além da própria fotossíntese realizada por algas durante a estação chuvosa, que pode aportar um volume considerável de carbono orgânico ao solo (Luizão \& Luizão, 1997).

Os efeitos de herbicidas sobre os microrganismos do solo têm sido geralmente relatados como temporários, especialmente em relação a biomassa microbiana do solo (Wardle $\&$ Parkinson, 1990) ou ao cultivo em laboratório (Wachowska \& Banaszkiewicz, 1999). No entanto, o uso de técnicas mais refinadas baseadas na extração direta e análise de ácidos nucléicos provenientes de amostras ambientais, têm demonstrado que o impacto sobre a comunidade microbiana pode ser expressivo. Em um desses estudos, El Fantroussi et al. (2000), através de DGGE mostraram efeitos deletérios da aplicação de herbicida do grupo fenil-uréia (linuron) sobre os microrganismos do solo expostos a este herbicida durante um período de 10 anos. Estes autores concluíram que o efeito negativo da aplicação de linuron se deu mais profundamente sobre bactérias não cultiváveis agrupadas em uma divisão chamada Acidobacterium, formada por bactérias versáteis na utilização e transformação de substratos orgânicos (Smit et al., 2001).

Atualmente, no Brasil, a soja é a cultura que mais utiliza herbicida, cerca de $40 \%$ do total comercializado (Spadotto, 2002). A maior parte do volume utilizado corresponde a herbicidas a base de glyphosate e o grupo das imidazolinonas. Estes herbicidas inibem duas importantes vias de síntese de aminoácidos, a via do chiquimato e a via dos aminoácidos ramificados, respectivamente. $\mathrm{E}$, embora, os efeitos sejam considerados brandos para animais, podem ser severos aos microrganismos (Wachowska \& Banaszkiewicz, 1999), pois estes possuem as duas vias de síntese de aminoácidos mencionadas (Bentley, 1990; Herrmann \& Weaver, 1999; Chipman et al., 1998; Duggleby \& Pang, 2000).

A dependência do ecossistema Lavrado a atividade microbiana, especialmente relacionada à ciclagem de nutrientes, associada aos efeitos negativos que os herbicidas podem ocasionar no equilíbrio microbiano do solo torna necessária uma avaliação do impacto ambiental dos sistemas de manejo do solo que estão se estabelecendo na região. Estas avaliações poderão auxiliar a identificação de quais manejos são adequados à manutenção da 
qualidade do solo e a sustentabilidade agrícola e ambiental da região (Smiderle et al., 2004).

Esse trabalho objetivou avaliar o efeito de herbicidas a base de glyphosate, imazaquin e trifluralin em dois diferentes manejos da cultura da soja: semeadura direta na palha e semeadura convencional. Foram realizadas avaliaçōes da biomassa microbiana do solo e evolução de $\mathrm{CO}_{2}$ do solo, avaliação da população bacteriana associada ao rizoplano de plantas de soja, através da técnica de PCR/DGGE e seqüenciamento do DNA bacteriano amplificado e avaliação da nodulação das plantas de soja.

\section{MATERIAL E MÉTODOS}

\section{DESCRIÇÃO DOS EXPERIMENTOS}

Entre os meses de maio e julho de 2003 foram conduzidos dois experimentos em áreas de cerrado de primeiro ano de cultivo em uma propriedade rural (Fazenda Novidade) no município de Alto Alegre RR, localizado a aproximadamente $100 \mathrm{~km}$ de Boa Vista. Estes experimentos foram conduzidos em dois sistemas de manejo do solo (semeadura direta na palha e semeadura convencional) que foram semeados com soja (cv. BRS Sambaiba), utilizando-se o cultivo em faixas com parcelas de $7 \times 7 \mathrm{~m}$ em delineamento experimental de blocos ao acaso, com três repetições.

A semeadura direta na palha $(\mathrm{SD})$ recebeu uma aplicação de $600 \mathrm{~kg} \mathrm{ha}^{-1}$ de fosfato natural (Dawi) e $2500 \mathrm{~kg} \cdot \mathrm{ha}^{-1}$ de calcário, seguido de duas gradagens no ano de 2002 e, no ano de 2003, semeou-se milheto 30 dias antes da implantação do experimento. Os tratamentos deste experimento foi dessecação do milheto com herbicida à base de glyphosate ( $\mathrm{N}$-(fosfometil) glicina) na dose de $0,7 \mathrm{~kg} \cdot \mathrm{ha}^{-1}$, dois dias antes da semeadura da soja, aplicação de herbicida à base de imazaquin, na dose de $0,5 \mathrm{~kg} \cdot \mathrm{ha}^{-1}$, em pré-emergência da cultura e um controle sem a aplicação de herbicida.

Na semeadura convencional (SC) também foi aplicado calcário e fosfato natural nas mesmas condiçōes da SD. Porém, diferiu por ter sido realizado uma capina com incorporação dos restos vegetais por ocasião da implantação do experimento e, sendo os tratamentos a aplicação, em pré-emergência da soja, de herbicida à base de imazaquin (ácido 2-[4,5-dihidro-4-metil-4-(1metiletil)-5-oxo-1H-imidazol-2-il]-3-quinolinacarboxílico) na dosagem de $0,5 \mathrm{~kg} \cdot \mathrm{ha}^{-1}$ e trifluralin (a,a,a-trifluoro-N-N-dipropilp-toluidina), na dosagem $0,3 \mathrm{~kg} \cdot \mathrm{ha}^{-1}$ e um controle sem a aplicação de herbicida.

A adubação de semeadura para os experimentos, consistiu de $540 \mathrm{~kg} \cdot \mathrm{ha}^{-1}$ do formulado NPK (02-20-20), mais micronutrientes e aplicação de cloreto de potássio em cobertura $\left(140 \mathrm{~kg} \cdot \mathrm{ha}^{-1}\right)$ aos 35 dias após a emergência da soja. $\mathrm{Na}$ semeadura, também foi realizada a inoculação das sementes de soja com o produto Biagro 10 (de acordo com recomendação do fabricante) que continha as estirpes de Bradyrhizobium japonicum SEMIA5079 e SEMIA5080.

A Tabela 1 apresenta o resultado da análise química do solo na profundidade de $0-20 \mathrm{~cm}$ nas áreas onde foram implantados os experimentos e também do cerrado nativo.

Tabela 1 - Análise química do solo de cerrado na profundidade de 0-20 cm em propriedade rural em Alto Alegre - Roraima.

\begin{tabular}{ccccccc}
\hline Amostras* & $\mathrm{pH}$ & $\begin{array}{c}\text { Matéria } \\
\text { orgânica }\end{array}$ & $\mathrm{Al}^{+3}$ & $\mathrm{Ca}^{+2}+\mathrm{Mg}^{+2}$ & $\mathrm{H}_{2} \mathrm{PO} 4+\mathrm{HPO4}^{-2}$ & $\mathrm{~K}^{+}$ \\
\cline { 4 - 7 } & $\mathrm{g} \mathrm{kg}^{-1}$ & \multicolumn{2}{c}{$\mathrm{cmolc} \mathrm{dm}^{-3}$} & $\mathrm{mg} \mathrm{dm}^{-3}$ & \\
\hline $\begin{array}{c}\text { Área } \\
\text { cultivada }\end{array}$ & 5,5 & 7 & 0,0 & 0,9 & 9 & 8 \\
$\begin{array}{c}\text { Cerrado } \\
\text { Nativo }\end{array}$ & 5,6 & 7 & 0,0 & 0,6 & 3 & 07 \\
\hline * Latossolo Amarelo com textura franco arenosa $\left(170 \mathrm{~g} \mathrm{~kg}^{-1} \mathrm{de}\right.$ argila $810 \mathrm{~g} \mathrm{~kg}^{-1} \mathrm{de}$ areia e
\end{tabular}

* Latossolo Amarelo com textura franco arenosa (170 g. $\mathrm{kg}^{-1}$ de argila, $810 \mathrm{~g} . \mathrm{kg}^{-1}$ de areia e

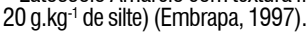

\section{COLETA DE AMOSTRAS}

A coleta de amostra de solo para a avaliação da biomassa microbiana do solo (BMS), evolução de $\mathrm{CO}_{2}$ e quociente metabólico $\left(q \mathrm{CO}_{2}\right)$ foi realizada nas áreas de $\mathrm{SD}$, SC e, também em uma área de cerrado nativo $(\mathrm{CN})$, como referência. As coletas foram realizadas logo antes da semeadura, na semeadura e aos 4 , 12, 28 e 60 dias após a semeadura da soja (DAS). A profundidade de coleta foi de $0-20 \mathrm{~cm}$, tendo sido realizadas quatro amostragens simples para compor uma amostra composta em cada parcela.

Aos 12, 28 e 60 dias após a semeadura foram coletadas amostras de raízes das plantas de soja para a extração do DNA dos microrganismos associados ao rizoplano das plantas. A coleta foi realizada eliminando-se a parte área da planta retirando-se um torrão de solo e procurando manter as raízes íntegras. Foram coletadas três plantas por parcela para compor cada uma das repetições dos tratamentos.

Depois de coletadas, as amostras de solo e raízes foram acomodadas em caixas de isopor e enviadas para análise na Embrapa Agrobiologia (Seropédica, RJ) por via aérea na temperatura ambiente, sendo o processamento realizado, no máximo 30 horas, após a coleta das amostras.

Aos 60 dias após a implantação do experimento avaliou-se a nodulação das plantas de soja através da contagem de nódulos das raízes das plantas de soja.

\section{AVALIAÇÃO DA BIOMASSA MICROBIANA DO SOLO}

Utilizou-se o método descrito por De-Polli \& Guerra (1997) adaptado de Vance et al. (1987), onde fracionou-se a amostra de solo em seis sub-amostras de $20 \mathrm{~g}$. Três destas sub-amostras foram inicialmente fumigadas com $\mathrm{CHCl}_{3}(1 \mathrm{~mL} ; 24 \mathrm{~h})$. Posteriormente, todas as repetições foram submetidas à extração com $\mathrm{K}_{2} \mathrm{SO}_{4}\left(50 \mathrm{ml} ; 0,5 \mathrm{~mol} . \mathrm{l}^{-1}\right)$ sob agitação $(30 \mathrm{mim} ; 500$ rpm). Após decantação (30 min), o extrato das amostras foi 
filtrado e uma alíquota de $8 \mathrm{ml}$ recebeu $2 \mathrm{ml} \mathrm{de} \mathrm{K}_{2} \mathrm{Cr}_{2} \mathrm{O}_{7}(0,066$ mol. $1^{-1}$ ) na presença de $10 \mathrm{ml} \mathrm{de} \mathrm{H}_{2} \mathrm{SO}_{4}$ e $2 \mathrm{ml} \mathrm{de}_{3} \mathrm{PO}_{4}$ concentrados. $\mathrm{O}$ excesso de $\mathrm{K}_{2} \mathrm{Cr}_{2} \mathrm{O}_{7}$ foi retrotitulado com $\left(\mathrm{NH}_{4}\right)_{2} \mathrm{Fe}\left(\mathrm{SO}_{4}\right)_{2} \cdot 6 \mathrm{H}_{2} 0\left(0,033\right.$ mol..$\left.^{-1}\right)$, revelando a quantidade de dicromato gasto na oxidação e conseqüentemente a quantidade de carbono extraída. Uma fração de solo $(10 \mathrm{~g})$ foi seca em estufa $\left(105^{\circ} \mathrm{C} ; 24 \mathrm{~h}\right)$ para a determinação da umidade das amostras.

\section{AVALIAÇÃO DA EVOLUÇÃO DE CO 2 E QUOCIENTE METABÓLICO} $\left(q \mathrm{CO}_{2}\right)$

A avaliação da respiração microbiana seguiu o procedimento descrito por Jenkinson \& Powlson, (1976). Fraçōes de $50 \mathrm{~g}$ de solo foram incubadas hermeticamente na presença de $\mathrm{NaOH}$ $\left(10 \mathrm{ml} ; 0,5 \mathrm{moll}^{-1}\right)$. Após um período de cinco dias, fez-se a precipitação do $\mathrm{CO}_{2}$ evoluído com $\mathrm{BaCl}_{2}(10 \%)$ e titulou-se o excesso de $\mathrm{NaOH}$ com $\mathrm{HCl}\left(0,5\right.$ mol. $\left.^{-1}\right)$.

O quociente metabólico foi estimado pela razão entre a respiração basal do solo pelo carbono da biomassa microbiana (Anderson \& Domsch, 1994).

\section{OBTENÇÃO DAS CÉLULAS MICROBIANAS DAS RAÍZES DAS PLANTAS DE SOJA}

Raízes finas das plantas de soja foram cortadas e lavadas em solução salina ( $\mathrm{NaCl}$ 0,85\%; 5 min) e secas em papel absorvente esterilizado. Em seguida pesou-se 1,0 g de raízes de cada repetição, que foi acondicionado em tubos cônicos $(50 \mathrm{ml})$ contendo 20 $\mathrm{ml}$ de $\mathrm{NaCl}(0,85 \%)$. Os tubos contendo as amostras foram, então, agitados horizontalmente ( $20 \mathrm{rpm} ; 30 \mathrm{~min})$. Deste extrato, retiraram-se $8 \mathrm{ml}$ que foram centrifugados $(8.000 \mathrm{rpm} ; 30 \mathrm{~min}$; $\left.4^{\circ} \mathrm{C}\right)$ e o precipitado formado armazenado $\left(12 \mathrm{~h} ; 20^{\circ} \mathrm{C}\right)$.

\section{EXTRAÇÃO DO DNA MICROBIANO}

Seguiu-se o protocolo descrito por Schwieger \& Tebbe (1998) e adaptado por Xavier et al. (2004). O precipitado microbiano estocado $\left(-20^{\circ} \mathrm{C}\right)$ foi ressuspenso em $0,6 \mathrm{ml}$ de tampão de lise TES $(0,05 \mathrm{M} \mathrm{NaCl}$; 0,01 M Na 2 -EDTA; 0,05 M Tris HCL pH 8,$0 ; 1 \%$ SDS) e agitado em vórtex. Em seguida, as amostras foram submetidas a cinco etapas de congelamento/ descongelamento: imersão em nitrogênio líquido ( $5 \mathrm{~min}$ ), agitação (1800 rpm; $10 \mathrm{seg})$ e aquecimento $\left(65^{\circ} \mathrm{C} ; 5 \mathrm{~min}\right)$. Aplicou-se, então, $8,4 \mathrm{ml}$ de proteinase $\mathrm{K}\left(20 \mathrm{mg} \cdot \mathrm{ml}^{-1}\right)$ nas amostras que foram incubadas sob agitação $\left(180 \mathrm{rpm} ; 65^{\circ} \mathrm{C} ; 1 \mathrm{~h}\right)$. Em seguida, adicionou-se, $0,6 \mathrm{ml}$ (um volume) de fenol-clorofórmio-álcool isoamílico (25:24:1) e centrifugou-se as amostras $(5.000 \mathrm{rpm} ; 6$ $\mathrm{min})$. O sobrenadante foi transferido cuidadosamente para novos tubos, onde foram adicionados $0,6 \mathrm{ml}$ (um volume) de clorofórmio-álcool isoamílico, repetindo-se a centrifugação anterior. Uma alíquota de aproximadamente $0,5 \mathrm{ml}$ do sobrenadante foi transferida para um novo tubo e 0,5 volumes de isopropanol gelado foram adicionados. As amostras foram, então, incubadas $\left(60 \mathrm{~min} ;-20^{\circ} \mathrm{C}\right)$ e centrifugadas $(13.000 \mathrm{rpm}$; $20 \mathrm{~min}$ ). Removido o sobrenadante, o precipitado foi centrifugado à vácuo para a secagem e ressuspendido em $50 \mathrm{ml}$ de tampão TE (10 mM Tris; 1 mM Na 2 -EDTA; pH 8,0).

\section{CONDIÇÕES DA PCR E DGGE}

Cada $35 \mathrm{ml}$ da reação consistiu de $1 \mathrm{ml}$ de DNA, tampão (10 mM), $\mathrm{MgCl}_{2}(3,5 \mathrm{mM})$, dNTP $(0,2 \mathrm{mM})$, Taq DNA polimerase (Invitrogen Cat. No. 11615-010) $(1,4 \mathrm{U})$ e os iniciadores $968 \mathrm{~F}-\mathrm{CG}$ e $1401 \mathrm{R}(0,2 \mathrm{mM}$ cada). Estes iniciadores e as condições da reação de PCR: aquecimento inicial $\left(95^{\circ} \mathrm{C} ; 3\right.$ min), 35 ciclos compostos de desnaturação $\left(94^{\circ} \mathrm{C} ; 30 \mathrm{seg}\right)$, anelamento $\left(55^{\circ} \mathrm{C} ; 30 \mathrm{seg}\right)$ e extensão $\left(72^{\circ} \mathrm{C} ; 30 \mathrm{seg}\right)$ e uma etapa final de extensão $\left(72^{\circ} \mathrm{C} ; 5 \mathrm{~min}\right)$ estão descritas em Gelsomino et al. (1999). Após a amplificação, os produtos das três reaçôes de $\mathrm{PCR}$, provenientes das diluiçôes, foram combinados em um único microtubo.

Um volume de 12 a $20 \mathrm{ml}$ de cada amostra de DNA amplificado foi aplicado em gel desnaturante de poli-acrilamida $6 \%$ (N-acrilamida, $\mathrm{N}^{\prime}$-metilbisacrilamida, 37:1) dissolvida em tampão TAE 0,5X (Tris-base, $20 \mathrm{mM} \mathrm{pH} \mathrm{7,8;} \mathrm{acetato} \mathrm{de} \mathrm{sódio}$ $10 \mathrm{mM} \mathrm{e} \mathrm{Na} \mathrm{N}_{2}$-EDTA, 0,5 mM). O gradiente de desnaturante utilizado foi de 50-65\%, obtido usando-se duas soluçōes, uma contendo apenas solução de poli-acrilamida e a outra uréia (7M) e formamida ( $40 \% \mathrm{v} / \mathrm{v})$ e, poli-acrilamida. A eletroforese foi realizada no sistema Dcode ${ }^{\mathrm{TM}}$ (Bio-Rad) sob voltagem constante $\left(120 \mathrm{~V} ; 60^{\circ} \mathrm{C} ; 16 \mathrm{~h}\right)$ e ao final o gel foi corado com uma solução de Syber Gold (Molecular Probe, $N^{\circ}$ Cat.S11494) (1X) e visualizado sob luz ultravioleta no sistema de foto-documentação IMAGO (B\&L).

As bandas de interesse foram retiradas do gel de DGGE com o auxílio de um bisturi cirúrgico, purificadas com o kit Qiaex II (Qiagen, $\mathrm{N}^{\circ}$ Cat. 20051) e ressuspensas em TE (10 mM Tris; 1 mM Na-EDTA; $\mathrm{pH} 8,0$ ). A reamplificação seguiu os mesmos passos da reação anterior (item 4), sendo o produto da reação purificado com o kit Wizard PCR Preps (Promega, $\mathrm{N}^{\circ}$ Cat. A7170) e seqüenciado em seqüenciador de DNA automático Mega BACE 1000 (Amersham Bioscience).

\section{ANÁLISE DOS DADOS}

Os dados gerados nos géis de DGGE foram analisados utilizando-se o coeficiente Jaccard e o método de agrupamento UPGMA, através do programa NTSYS-PC V. 2.10 (Applied Biostatistics). Os dados de biomassa microbiana, evolução de $\mathrm{CO}_{2}$ e $q \mathrm{CO}_{2}$ foram submetidos à análise de variância pelo teste $F(p \leq 0,05)$.

\section{RESULTADOS E DISCUSSÃO}

\section{BIOMASSA, RESPIRAÇÃO E QUOCIENTE METABÓLICO DA COMUNIDADE MICROBIANA DO SOLO}

Em todos os tratamentos e também no cerrado nativo os valores médios de BMS variaram entre 60 e $200 \mathrm{mg}^{-g^{-1}} \mathrm{de}$ 
carbono microbiano em solo seco (Tabela 2; Figura 1), que são valores considerados baixos, para ambientes tropicais (Feigl et al., 1998). Provavelmente isto está relacionado ao baixo teor de matéria orgânica observado no solo dos experimentos (Tabela 1), que juntamente com a sazonalidade pluvial, são fatores, limitantes ao desenvolvimento microbiano (Vance \& Nadkarni, 1990; Sparling et al., 1994).

Tabela 2 - Média dos valores de biomassa microbiana do solo (BMS), evolução de $\mathrm{CO}_{2}$ do solo e quociente metabólico $\left(q \mathrm{CO}_{2}\right)$ das coletas aos 4 , 12,28 e 60 dias após o plantio da soja em área de semeadura direta na palha e semeadura convencional.

\begin{tabular}{|c|c|c|c|c|c|c|}
\hline Tratamento & $\begin{array}{r}\mathrm{B} \\
\left(\mu \mathrm{g} \cdot \mathrm{g}^{-1}\right. \\
\mathrm{SC}\end{array}$ & C no & $\begin{array}{l}\text { Evolu } \\
(\mu \mathrm{g} \text { de } \mathrm{C}\end{array}$ & $\begin{array}{l}\mathrm{CO}_{2} \\
\left.\text { solo } h^{-1}\right)\end{array}$ & (ng de $\mathrm{CO}_{2}$ & $\begin{array}{l}q_{\mathrm{CO}_{2}} \\
{ }_{2} \cdot \mu \mathrm{g}^{-1} \text { de BMS-C.h-1) }\end{array}$ \\
\hline \multicolumn{7}{|c|}{ Semeadura direta na palha (SD) } \\
\hline Controle & 91,3 & a & 0,9 & $a b$ & 9,9 & $a b$ \\
\hline Glyphosate & 107,4 & a & 0,6 & $\mathrm{~b}$ & 5,6 & b \\
\hline $\begin{array}{l}\text { Glyphosate+ } \\
\text { Imazaquin }\end{array}$ & 71,3 & $b$ & 1,1 & a & 15,4 & a \\
\hline CV (\%) & 20,7 & & 43,2 & & 86,2 & \\
\hline \multicolumn{7}{|c|}{ Semeadura convencional (SC) } \\
\hline Controle & 71,1 & ns & 1,0 & ns & 12,7 & ns \\
\hline Imazaquin & 74,1 & ns & 0,9 & ns & 8,1 & ns \\
\hline Trifluralin & 74,9 & ns & 0,9 & ns & 14,7 & ns \\
\hline CV $(\%)$ & 22,9 & & 50,7 & & 49,9 & \\
\hline \multicolumn{7}{|c|}{ Comparação dos controles com o Cerrado Nativo } \\
\hline $\begin{array}{l}\text { Cerrado } \\
\text { Nativo }\end{array}$ & 142,6 & a & 0,84 & ns & 5,9 & ns \\
\hline Controle - SD & 91,3 & $b$ & 0,9 & ns & 9,9 & ns \\
\hline Controle - SC & 71,1 & c & 0,9 & ns & 12,7 & ns \\
\hline CV (\%) & 27,4 & & 41,7 & & 45,7 & \\
\hline
\end{tabular}

* Valores seguidas da mesma letra no SD, SC ou na comparação dos controles com o CN no mesmo parâmetro, não diferem estatisticamente entre si, em nível de $5 \%$ de

probabilidade pelo teste de Tukey.

probabilidade pelo teste de

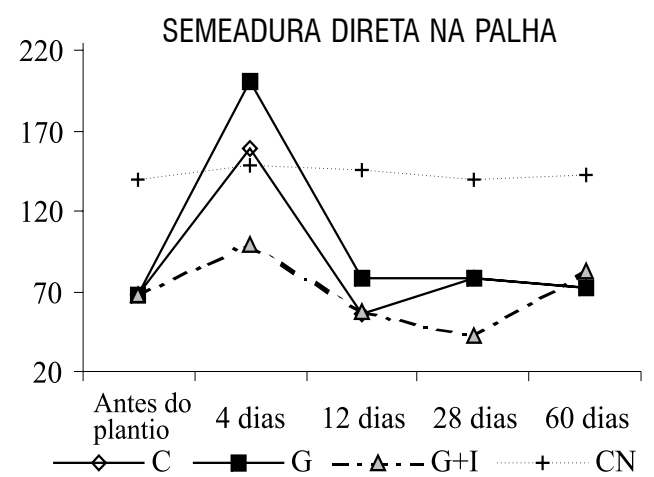

Na Tabela 2, observa-se que a maior BMS ocorreu no solo da área de cerrado nativo, seguido do solo da área de SD e SC. O comportamento da BMS foi bastante distinto em cada uma das áreas (Figura 1). No cerrado nativo não ocorreu variação significativa do teor de carbono da biomassa microbiana ao longo do período de estudo. $\mathrm{NaSD}$, todos os tratamentos apresentaram aumento expressivo da BMS, 4 dias após a semeadura da soja. Particularmente, o tratamento com glyphosate resultou num aumento de BMS três vezes maior em relação ao valor obtido após a semeadura, seguido de uma diminuição 12 dias após a semeadura da soja. $\mathrm{Na}$ área de $\mathrm{SC}$ houve uma tendência de aumento contínuo dos valores médios da BMS ao longo do período de estudo (Figura 1).

Estes resultados corroboram dados de redução da BMS observados na conversão de ambientes considerados estáveis, como as florestas, em lavoura e, a semeadura do solo com cobertura de palhada, como ocorreu na área de SD tende a manter uma maior biomassa microbiana, comparada à semeadura em solo exposto, como ocorreu na SC (Feigl et al., 1998; Ferreira, 2002).

$\mathrm{O}$ fato de a biomassa microbiana ter aumentado significativamente na área de $\mathrm{SD}$ aos quatro dias após a semeadura da soja deve ser conseqüência do preparo do solo através da abertura do sulco e a adubação de semeadura e, principalmente o início da decomposição dos resíduos vegetais radicualres (Pereira et al., 1999). Por outro lado, o aumento gradativo da BMS na SC, provavelmente seja decorrente ao estresse inicial sofrido pela comunidade microbiana, em função do revolvimento do solo, por ocasião do preparo, e a posterior aceleração da decomposição da matéria orgânica, influenciada pela aeração do solo (Pereira $e t$ al., 1999). Nota-se, também, que a cultura da soja passou a influenciar grandemente a BMS, isto porque a partir dos 28 dias a BMS em ambas as áreas dos experimentos se tornaram muito semelhantes.

Efeito significativo de herbicidas sobre a BMS ao longo das coletas foram apenas observados na área de SD aos quatro dias após a semeadura (Figura 1; Tabela 2), onde os teores de carbono

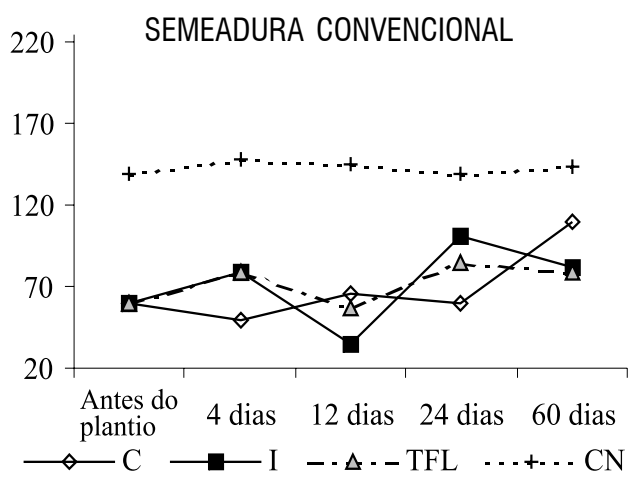

Figura 1 - Variação da biomassa microbiana do solo ( $\mu \mathrm{g}^{-1}$ de $\mathrm{C}$ no solo), ao longo de um período de 60 dias, em experimento de soja utilizando a aplicação de diferentes herbicidas. C - controle, G - glyphosate, I - imazaquin, TFL - trifluralin e CN - cerrado nativo. 
microbiano do tratamento com o herbicida a base de glyphosate + imazaquin foi significativamente menor do que o tratamento controle e o tratamento somente com glyphosate. Este resultado sugere que o imazaquin seja capaz de ocasionar uma redução da BMS, uma vez que o tratamento que recebeu apenas glyphosate promoveu um aumento dos valores de BMS, associados a níveis de $q \mathrm{CO}_{2}$ que tenderam a se aproximar dos níveis encontrados no cerrado nativo (Tabela 2). Redução nos teores de carbono da biomassa microbiana também foram verificados por Perucci et al. (2000) e Li et al. (2004) em condiçôes de campo, para o herbicida imazapyr que pertence ao mesmo grupo químico do imazaquin.

O efeito do imazaquin sobre os microrganismos do solo provavelmente decorre da inibição da enzima acetolactato sintase (ALS), enzima chave da síntese de aminoácidos ramificados (Chipman et al., 1998; Duggleby \& Pang, 2000). Entretanto, existe uma carência muito grande de estudos de impacto ambiental, tanto com o herbicida imazaquin, quanto com outros herbicidas do grupo das imidazolinonas que atuam sobre a enzima acetolactato sintase. Este grupo de herbicidas foi introduzido no mercado na década de 80 e apresenta baixa toxicidade para animais, o que pode explicar a lacuna de trabalhos de pesquisa nesta área.

O aumento da BMS, em função da aplicação do herbicida à base de glyphosate também foi relatado por outros autores, especialmente associado ao aumento da mineralização do nitrogênio e carbono (Haney et al., 2000; Busse et al., 2001). Nesses estudos, o efeito esteve, aparentemente, ligado a capacidade dos microrganismos utilizarem a molécula do glyphosate como fonte de C, N e P (Busse et al., 2001).

$\mathrm{Na}$ área de SC o efeito dos herbicidas pode ter sido mascarado pelo preparo do solo com uma capina e conseqüente incorporação dos restos vegetais antes da semeadura da soja. O revolvimento do solo pode ocasionar alterações no solo como a maior aeração, maior exposição ao sol e decomposição da matéria orgânica, os quais podem ter alterado de forma mais intensa a biomassa microbiana do que propriamente os herbicidas. Em outros estudos os efeitos dos herbicidas trifluralin e imazaquin, embora variados, foram observados em condiçōes de campo (Boldt \& Jacobsen; 1998; Hang et al., 2001; Li et al., 2004).

\section{COMUNIDADE BACTERIANA ASSOCIADA AO RIZOPLANO DE SOJA}

Os géis de DGGE, inicialmente, foram realizados para cada um dos manejos do solo, dentro de cada coleta. Observou-se, de forma geral, que os perfis eletroforéticos apresentaram baixo número de bandas, variando entre 5 e 17. Este baixo número de bandas pode estar associado às condiçôes edafoclimáticas da região, especialmente o baixo teor de matéria orgânica e a sazonalidade pluvial, que podem limitar as atividades microbianas (Vance \& Nadkarni, 1990; Sparling et al., 1994). Tendo havido reduzido número de bactérias nas raízes de soja é possível que estas não tenham sido detectadas no DGGE, haja vista, que esta técnica mostra, preferencialmente, grupos microbianos mais abundantes.

A partir dos perfis de bandas dos géis de DGGE em cada uma das coletas, foram elaborados dendrogramas para cada um dos sistemas de manejo do solo, utilizando-se para o cálculo da similaridade o coeficiente de Jaccard e o método UPGMA (método de pareamento de grupos atribuindo pesos iguais) para o agrupamento (Figura 2). Na área de $\mathrm{SD}$, os padrōes da comunidade bacteriana das repetiçóes do tratamento com herbicida à base de glyphosate sempre se agruparam mais próximos ao padrão bacteriano do controle, do que àquelas do tratamento com herbicida à base de glyphosate + imazaquin. A similaridade média das três repetiçôes do tratamento com glyphosate em relação ao controle ficou acima de $60 \%$ nas três coletas, enquanto para o tratamento glyphosate + imazaquin isto só ocorreu na coleta realizada aos 28 dias (Figura 3), o que indica maior impacto do imazaquin à comunidade bacteriana. $\mathrm{Na}$ área de SC, também, observou-se a tendência do perfil da comunidade bacteriana do controle manter-se mais afastada do tratamento com imazaquin, sobretudo na coleta 1 , comparado ao tratamento com trifluralin (Figura 2). Porém, houve grande variação da similaridade entre as repetições de cada tratamento, o que restringiu o agrupamento destas repetições.

Os perfis de bandeamento nos géis de DGGE das coletas aos 12 e 60 dias estão apresentados nas Figuras 4 A e B. Na área de PD (Figura 4A) observou-se o desaparecimento de bandas tanto do tratamento que recebeu a aplicação de herbicidas à base de glyphosate, quanto glyphosate + imazaquin. Entretanto, não somente o desaparecimento de bandas foi observado, mas também o surgimento de algumas outras esporádicas em diferentes repetiçôes dos tratamentos com herbicidas.

$\mathrm{Na}$ área de SC, observou-se nitidamente um aumento do número de bandas da primeira para a última coleta, indicando aumento da riqueza de bactérias (Figura 4B). Observaram-se, também, diferenças no padrão de bandeamento entre as repetições de um mesmo tratamento, o que dificultou a detecção de efeitos proporcionados pelos herbicidas, muito embora algumas bandas ocorreram de forma destacada entre as repetiçōes do tratamento à base de imazaquin.

A avaliação dos perfis de DGGE e dos respectivos agrupamentos em cada uma das áreas indica que os herbicidas reduziram a similaridade da comunidade bacteriana em relação ao controle. $\mathrm{Na}$ área de $\mathrm{SD}$, o tratamento com herbicida à base de glyphosate e imazaquin resultou em maiores alteraçōes na comunidade bacteriana em comparação com o controle, do que o tratamento apenas com herbicida à base de glyphosate, sugerindo efeitos mais severos do imazaquin. Enquanto na área de SC, de forma geral, houve aumento da riqueza de bandas da primeira para a última coleta, acompanhando o aumento observado para a BMS e também variações entre os perfis de 
SEMEADURA DIRETA NA PALHA
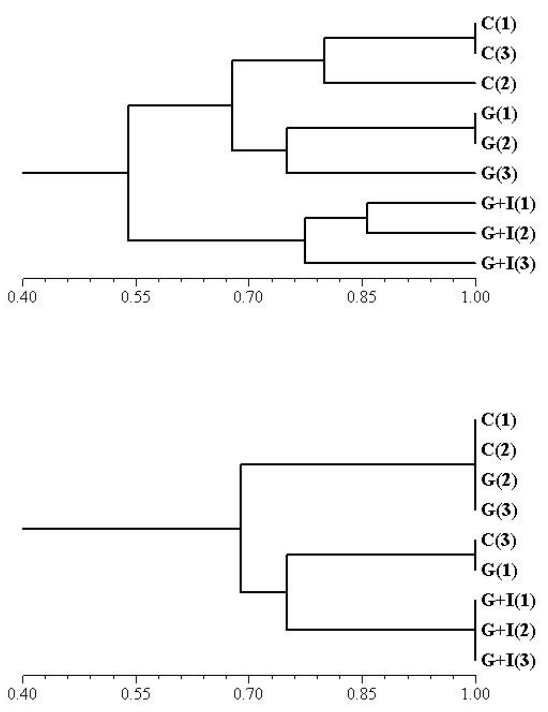

$60 \mathrm{DAS}$

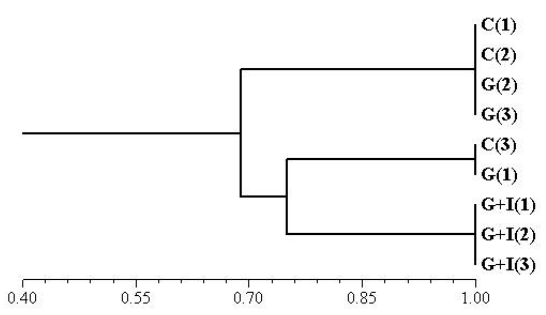

SEMEADURA CONVENCIONAL

12 DAS

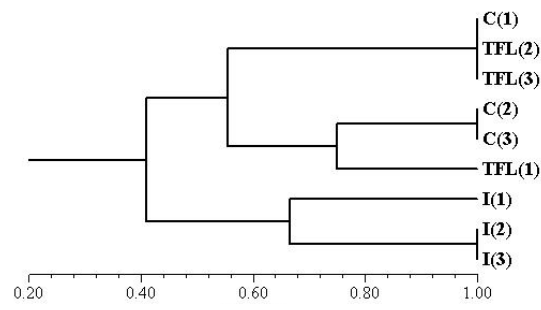

28 DAS
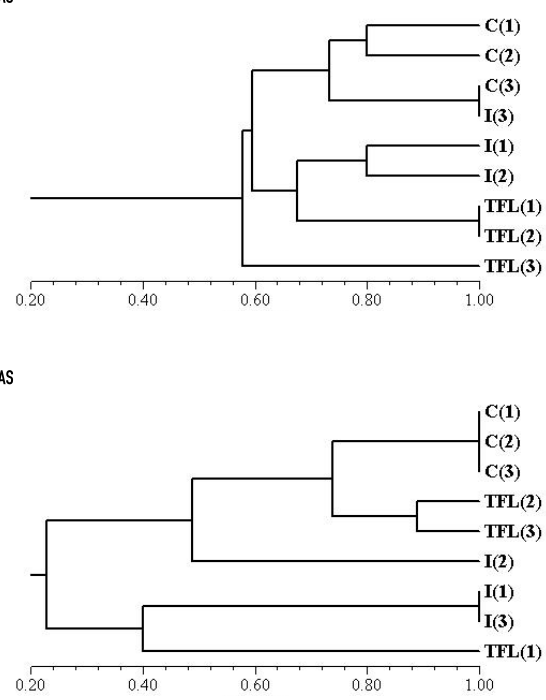

Figura 2 - Similaridade entre os perfis bacterianos de amostras de rizoplano de plantas de soja obtidos por DGGE em experimentos tratados com diferentes herbicidas em dois sistemas de manejo do solo em área de cerrado no Estado de Roraima aos 12, 28 e 60 dias após a semeadura da soja. DAS -dias após a germinação, C - controle, G - glyphosate, I - imazaquin e TFL - trifluralin. 0 número entre parênteses indica a repetição de cada tratamento.

SEMEADURA DIRETA NA PALHA

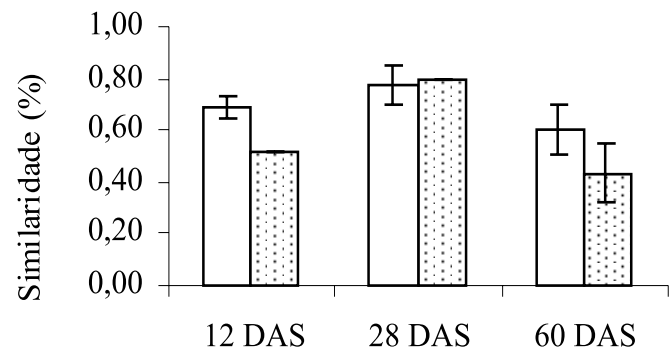

$\square$ Glifosato $\quad \square$ Glifosato + imazaquin
SEMEADURA CONVENCIONAL

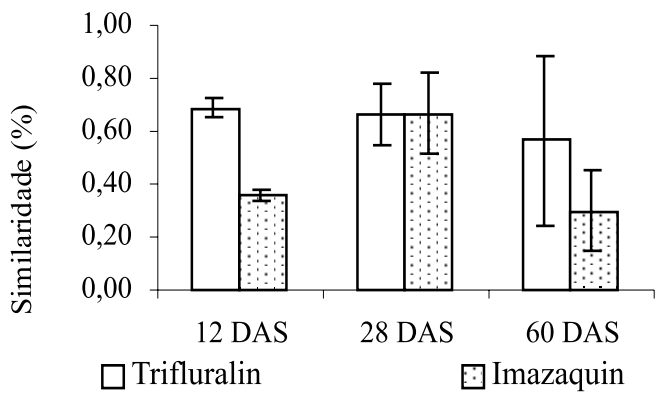

Figura 3 - Similaridade média entre os padrões de bandas (obtidas em gel de DGGE) dos tratamentos com herbicidas em relação ao controle, em dois sistemas de manejo do solo. As barras no gráfico indicam o erro padrão entre as repetições. DAS - dias após a semeadura. 
DGGE de repetições de um mesmo tratamento. Esta heterogeneidade observada entre os perfis de bandeamento, provavelmente, é decorrente do preparo do solo, uma vez que as práticas agrícolas de manejo do solo como a aração, adubação e a calagem alteram a aeração do solo, a decomposição da matéria orgânica, a disponibilização de nutrientes e o pH do solo. E, estas alteraçôes influenciam nos processos bioquímicos do solo e por conseqüência a estrutura da comunidade bacteriana do solo (Kamel et al., 1989; Pereira et al., 1999).

Oito das bandas ocorridas nos géis de DGGE (Figuras 4 e 5 ) foram isoladas, reamplificadas, seqüenciadas e submetidas à análise de homologia com seqüências do rDNA depositadas no National Center for Biotechnology Information (NCBI), através do programa BLAST (Altshul et al., 1997). No experimento na área de SD observou-se que uma seqüência com $90 \%$ de homologia com Herbaspirillum sp., somente estava presente no tratamento controle, o que sugere um efeito do herbicida à base de glyphosate sobre o desenvolvimento de bactérias com reconhecida importância ecológica (Valverde et al., 2003). Na área de SC, uma banda com seqüência com $92 \%$ de homologia com Massilia timonae, que estava presente no controle e em duas repetiçōes do tratamento com glyphosate, aparentemente foi inibida pela presença do imazaquin. Por outro lado, na SC, observou-se que uma seqüência com $96 \%$ de homologia com uma seqüência de Ralstonia sp. foi aparentemente estimulada no tratamento com imazaquin. Esta observação sugere que o imazaquin possa propiciar uma interação sinergística com algumas bactérias do solo (Johal \& Rahe, 1984), fornecendo uma vantagem competitiva, que pode estar relacionada com a habilidade da bactéria em degradar a molécula do herbicida (Cantwell et al., 1989), ou ao fato do herbicida inibir microrganismos antagonistas (Ahmed et al., 1995). Isto é um fato importante, uma vez que o gênero Ralstonia engloba bactérias fitopatogênicas (Schönfeld et al., 2003).
Para o herbicida glyphosate já foi observada a existência de interação sinergística com vários microrganismos fitopatogênicos do solo, tais como Pythium (Descalzo et al., 1998), Fusarium (Levesque et al., 1993) e Rhizoctonia (Smiley et al., 1992). A potencialização do risco do surgimento de doenças em plantas em função da aplicação de herbicidas também foi estudada por Heydari et al. (1997), quando observaram que os herbicidas pendimethalin, prometrina e trifluralin ocasionaram reduçôes no número de Pseudomonas e Burkholderia que apresentavam reconhecido efeito supressivo sobre algumas doenças em plantas de algodão.

As outras cinco bandas seqüenciadas que apresentaram pelo menos $92 \%$ de homologia com bactérias dos gêneros Burkholderia, Thiomonas e Pseudomonas (Figuras 4 e 5), mostraram-se tolerantes aos herbicidas testados, mostrando que bactérias que participam de importantes processos ecológicos do solo como a fixação biológica de nitrogênio, controle biológico, produção de promotores de crescimento vegetal e decomposição de matéria orgânica não são afetadas pelos herbicidas utilizados (van Elsas \& Heijnen, 1990; Moreira \& Amils, 1997).

Este trabalho foi um dos primeiros realizados em solo de cerrado do Estado de Roraima, utilizando PCR/DGGE para avaliar a composição bacteriana associada ao rizoplano de plantas de soja. De forma marcante, observou-se baixa abundância de bactérias colonizando as raízes de plantas de soja, sugerindo que as peculiaridades deste ecossistema, como por exemplo, o baixo teor de matéria orgânica e a sazonalidade pluviométrica são determinantes da composição microbiológica do solo. Também foram identificados efeitos da aplicação dos herbicidas à base de glyphosate e imazaquin sobre as bactérias do solo, inclusive bactérias com alta homologia com seqüências de rDNA 16 S de bactérias ecologicamente importantes. Entretanto, estas avaliaçôes demandam a continuidade dos estudos, de forma a atestar o impacto do uso de herbicidas e outras práticas agrícolas sobre os microrganismos do solo.

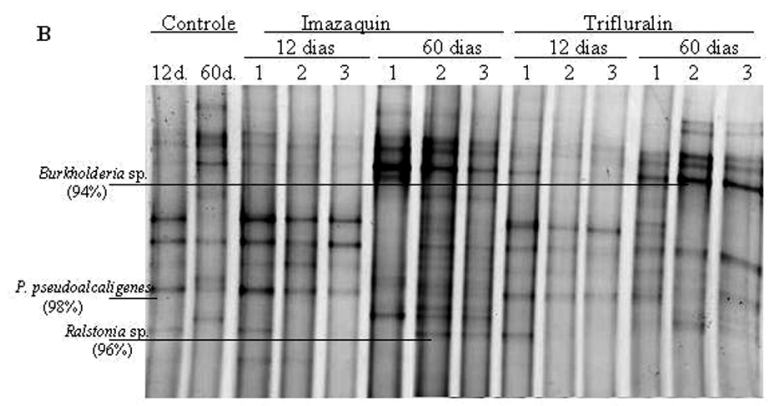

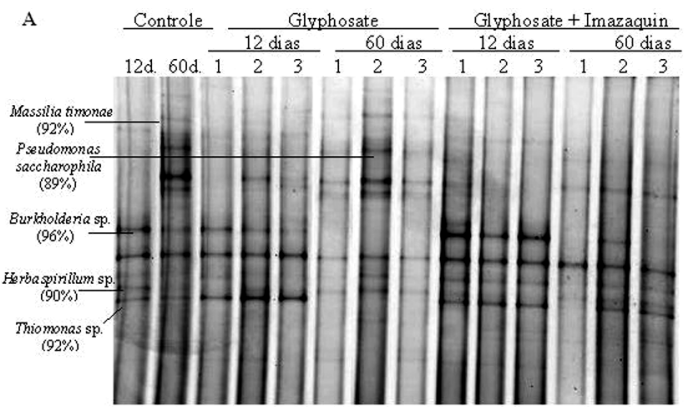

Figura 4 - Perfis bacterianos obtidos em DGGE representativos da comunidade bacteriana do rizoplano de plantas de soja aos 12 e 60 dias após a aplicação dos herbicidas. As espécies bacterianas indicadas compreendem as bandas retiradas dos géis, seqüenciadas e submetidas à análise de homologia com seqüências de DNA 16SrDNA depositadas no NCBI, utilizando o programa BLAST para a análise. Os números entre parêntese indicam a similaridade entre as seqüências analisadas e as depositadas no NCBI. A - área de semeadura direta na palha e B - semeadura convencional. 


\section{NODULAÇÃO DAS PLANTAS DE SOJA}

Visualmente aos 60 dias, não foram observadas diferenças de nodulação entre os tratamentos, sendo o número médio de nódulos por plantas entre 30 e 69. De forma geral, os nódulos apresentavam-se bem formados e ativos quanto à fixação biológica de nitrogênio. Também não foram observadas diferenças estatísticas no número de nódulos entre os diferentes tratamentos (dados não apresentados).

O efeito dos herbicidas na nodulação de plantas leguminosas tem sido considerado controverso, principalmente em decorrência das características do herbicida, da sua mobilidade no ambiente e do nível de tolerância do rizóbio (De-Polli et al., 1986).

Efeitos do imazaquin sobre a fixação biológica de nitrogênio foram mostrados por Silva et al., (1998) em uma concentração de $0,15 \mathrm{~kg} \cdot \mathrm{ha}^{-1}$ de ingrediente ativo Os autores observaram que o imazaquin reduziu significativamente o número de nódulos e atividade da nitrogenase até aos 80 dias após a semeadura do caupi. Entretanto, Gonzáles et al. (1999) não observaram efeitos na nodulação de plantas de soja.

Em relação ao trifluralin, Mendes et al. (1990) observaram que a tolerância diferenciada de estirpes de Bradyrhizobium sp. a este herbicida pode significar uma vantagem competitiva. Estes autores observaram que a estirpe CPAC 15 aumentou em cerca de $15 \%$ a ocupação nodular quando houve a aplicação do trifluralin. Por outro lado, nos tratamentos inoculados com as estirpes $74 \mathrm{~K}$ e $8 \mathrm{~W}$, o herbicida reduziu em cerca de $20 \%$ a ocupação nodular.

No caso do glyphosate, apesar deste apresentar efeito severo sobre os rizóbios em condições de cultivo, em condições de campo este é, de forma geral, reduzido (Mallik \& Tesfai, 1985). Entretanto, especial atenção passou a merecer a utilização da soja transgênica resistente ao glyphosate, uma vez que o herbicida aplicado sobre as folhas das plantas poderia ser translocado para o interior dos nódulos, reduzindo a atividade da enzima 5-enolpirovil-chiquimato-3-fosfato sintase (EPSPS) nos bacteróides e, em conseqüência o processo de FBN. Neste sentido, King et al. (2001), estudando soja tolerante ao glyphosate mostraram que em alguns cultivares pode haver um retardamento do início da atividade de FBN, reduzindo a fixação de $\mathrm{N}$ nos primeiros estádios de desenvolvimento das plantas de soja.

Os resultados discutidos em relação à nodulação das plantas de soja em sistemas de manejo do solo utilizando herbicidas para o controle de plantas daninhas ainda são preliminares, demandando outros estudos que avaliem as estirpes formadoras de nódulos, assim como a determinação do teor de $\mathrm{N}$ fixado pela simbiose.

\section{BIBLIOGRAFIA CITADA}

Ahmed, I.; Bissett, J.; Malloch, D. 1995. Influence of bioherbicide phosphinothricin on interaction between phytopathogens and their antagonists. Canadian Journal of Botany, 73(11):1750-1760.

Altschul, S.F.; Madden, T.L.; Schaffer, A.A.; Zhang, J.; Zhang, Z.; Miller, W.; Lipman, D.J. 1997. Gapped BLAST and PSI-BLAST: a new generation of protein database search programs. Nucleic Acids Research, 25(17):3389-3342.

Anderson, T.H.; Domsch, K.H. 1994. Application of ecophysiological quotients $\left(q \mathrm{CO}_{2}\right.$ and $\left.q \mathrm{D}\right)$ on microbial biomasses from soils of different cropping histories. Soil Biology and Biochemistry, 22(2):251-255.

Bentley, R. 1990. The shikimate pathway - a metabolic tree with many branches. Critical Review in Biochemistry o Molecular Biology, 35(4):. 307-384.

Boldt, T.S.; Jacobsen, C.S. 1998. Different toxic effects of the sulfonylurea herbicides metsulfuron methyl, chlorsulfuron and thifensulfuron methyl on fuorescent pseudomonads isolated from an agricultural. FEMS Microbiology Letters, 161(1):29-35.

Busse, M.D.; Ratcliff, A.W.; Schestak, C.J.; Powers, R.F. 2001. Glyphosate toxity and effect on long-term vegetation control on soil microbial communities. Soil Biology and Biochemistry, 33(12/1):1777-1789.

Cantwell, J.R.; Liebl, R.A.; Slife, F.W. 1989. Biodegradation characteristics of imazaquin and imazethapyr. Weed Science, 37(8):815-819.

Chipman, D.; Barak, Z.; Schloss, J.V. 1998. Biosynthesis of 2-aceto2-hydroxy acids: acetolactate synthases and acetohydroxyacid synthases. Biochimica et Biophysica Acta, 1385(3):401-419.

De-Polli, H.; Guerra, J.G.M. 1997. Determinação do carbono da biomassa microbiana do solo: método de fumigação-extração. Seropédica: Embrapa Agrobiologia, 10p. (Embrapa Agrobiologia. Documentos, 37).

De-Polli, H.; Souto, S.M.; Franco, A.A. 1986. Compatibilidade de agrotóxicos com Rhizobium spp. e a simbiose das leguminosas. Seropédica: Embrapa Agrobiologia, 71p. (Embrapa Agrobiologia. Circular Técnica, 1).

Descalzo, R.D.; Punja, Z.K.; Lévesque, C.A. Rahe, J.E. 1998. Glyphosate treatment of bean seedlings causes short-term increases in Pythium populations and damping off potential in soils. Applied Soil Ecology, 8(1):25-33.

Duggleby, R.G.; Pang, S.S. 2000. Acetohydroxyacid synthase. Journal of Biochemistry and Molecular Biology, 33(1):1-36.

El Fantroussi, S.; Verstraete, W.; Top, E.M. 2000. Enrichment and molecular characterization of a bacterial culture that degrades methoxy-methyl urea herbicides and their aniline derivatives. Applied Environmental Microbiology, 66(3):5110-5115.

Empresa Brasileira de Pesquisa Agropecuária - Embrapa. 1997. Manual de métodos de análise de solos. (2.ed.). Centro Nacional de Pesquisa de Solos, Rio de Janeiro, 211pp. 
Feigl, B. J.; Cerri, C. C.; Bernoux, M. 1998. Balanço do carbono e biomassa em solos na Amazônia. In: MELO, I. S.; AZEVEDO, J. L., (Eds). Ecologia Microbiana. EMBRAPA Meio Ambiente. Jaguariúna, São Paulo. p. 423-441.

Ferreira, E.P.B. 2002. Impacto de sistemas de manejo do solo e rotação de culturas sobre a funcionalidade e a diversidade da microbiota do solo. Dissertação de Mestrado, Universidade Federal Rural do Rio de Janeiro, Seropédica, Rio de Janeiro. 119pp.

Gelsomino, A.; Keijzer-Wolters, A.C.; Cacco G.; Van Elsas, J.D. 1999. Assessment of bacterial community structure in soil by polymerase chain reaction and denaturing gradient gel electrophoresis. Journal of Microbiological Methods, 38(1):1-15.

Gianluppi, D. 1997. Características pedoclimáticas dos cerrados. Boa Vista: Embrapa Roraima, 2p. (Embrapa Roraima. Embrapa Informa, 004).

Gianluppi, D.; Gianluppi, V.; Smiderle, O.J. 2000. Recomendaçôes técnicas para cultivo da soja nos cerrados de Roraima - 1999/2001. Boa Vista: Embrapa Roraima, 28p. (Embrapa Roraima. Circular Técnica, 1).

Gianluppi, D.; Smiderle, O.J. 2003. Agricultura nos cerrados de Roraima. Revista Plantio Direto, 61(9):29-31.

Gianluppi, V.; Smiderle, O.J.; Gianluppi, D. 2004. Plantio Direto de soja em capim nativo nos cerrados de Roraima. In: Reunião de Pesquisa de Soja da Região Central do Brasil, 2004. Anais... Embrapa Soja, Fundação Meridional, Londrina. p.110.

González, N.; Eyherabide, J. J.; Barcelonna, M. I.; Gaspari, A.; Sanmartino, S. 1999. Effect of soil interacting herbicides on soybean nodulation in balcarce, Argentina. Pesquisa Agropecuária Brasileira, 10(34):1167-1173.

Haney, R.L.; Senseman, S.A.; Hons, E.M.; Zuberer, D.A. 2000. Effect of glyphosate on soil microbial activity and biomass. Weed Science, 48(1):89-93.

Hang, M.; Zhogyun, C.; Yuhua, Z.; Meichi. 2001. Effects of trifluralin on soil microbial populations and the nitrogen fixation activities. Journal of Environmental Science and Health, 36(4):569579.

Herrmann, K. M.; Weaver, L. M. 1999. The shikimato pathway. Annual Review of Plant Physiology and Plant Molecular Biology, 50(60):473-503.

Heydari, A.; Misaghi, I.J.; Mccloskey, W.B. 1997. Effects of three soil-applied herbicides on populations of plant disease suppressing bacteria in the cotton rhizosphere. Plant and Soil, 195(1):75-81.

Jenkinson, D.S.; Powlson, D.S. 1976. The effects of biocida treatment on metabolism in soil. Method for measuring soil biomass. Soil Biology and Biochemistry, 8(2):209-213.

Johal, G.S.; Rahe, J.E. 1984. Effect of soilborn plant pathogenic fungi on the herbicidal action of glyphosate on bean seedlings. Phytopathology, 74(7):950-955.

Kamel, Z.; Khalil, M.S.; Shalaby, A.M. 1989. Calcium and biological activities of two Streptomyces species isolated, from the rrhizosphere of soybean plants. Journal of Basic Microbiology, 29(1):31-39.
Kennedy, A. C. 1999. Bacterial diversity in agroecosystems. Agriculture, Ecosystems and Environment, 74(1):65-76.

King, C.A.; Purcell, L.C.; Vories, E.D. 2001. Plant growth and nitrogenase activity of glyphosate-tolerant soybean in response to foliar glyphosate application. Agronomy Journal, 93(2):179186.

Levesque, C.; Rahe, J.E.; Eaves, D.M. 1993. Fungal colonization of glyphosate-treated seedlings using a new root plating technique. Mycological Research, 97(3):299-306.

Li, Q.; Allen, H.L.; Wollum II, A.G. 2004. Microbial biomass and bacterial functional diversity in forest soils: effects of organic matter removal, compaction, and vegetation control. Soil Biology \& Biochemistry, 36(4):571-579.

Luizão, F.J.; Luizão, R.C.C. 1997. Matéria orgânica do solo em Roraima. In: Barbosa, R. I.; Ferreira, E. J .G.; Castellón, E. G. (Eds). Homem, ambiente e ecologia no estado de Roraima. Instituto Nacional de Pesquisa da Amazônia (INPA). Manaus, Amazonas. p.363-379.

Mallik, M.A.B.; Tesfai, K. 1985. Pesticidal effect of soybean-rhizobia symbiosis. Plant and Soil, 85(1):33-41.

Mendes, I.C.; Peres, J.R.R.; Suhet, A.R.; Vargas, M.A.T. 1990. Efeito do trifluralin na ocorrência de estirpes de Bradyrhizobium japonicum em solos com população estabelecida. Brasília: Embrapa Cerrados, 6p. (Pesquisa em andamento).

Moreira, D.; Amils, R. 1997. Phylogeny of Thiobacillus cuprinus and Other Mixotrophic Thiobacilli: Proposal for Thiomonas gen. nov. International Journal of Systematic Bacteriology, 47(2):522528.

Pereira, J.C.; Neves, M.C.P.; Drozdowicz, A. 1999. Dinâmica das populaçóes bacterianas em solos de cerrados. Pesquisa Agropecuária, 34(5):801-811.

Perucci, P.; Dumontet, S.; Bufo, S.A.; Mazzatura, A.; Casucci, C. 2000. Effects of organic amendment and herbicide treatment on soil microbial biomass. Biology and Fertility of Soils, 32(1):1723.

Schönfeld, J.; Heuer, H.; Van Elsas, J.D.; Smalla, K. 2003. Specific and Sensitive Detection of Ralstonia solanacearum in Soil on the Basis of PCR Amplification of fliC Fragments. Applied and Environmental Microbiology, 69(12):7248-7256.

Schwieger, F.; Tebbe, C.C. 1998. A new approach to utilize PCRsingle-strand-conformation polymorphism for $16 \mathrm{~S}$ rRNA genebased microbial community analysis. Applied Environmental Microbiology, 64(12):4870-4876.

Silva, J.C.; Colaço, W.; Burity, H.A.; Frreira, N.C.M.; Figueiredo, M. V.B.; Martinez, C.R. 1998. Herbicidas na nodulAção e na fixação de $\mathrm{N}_{2}$ em caupi. Pesquisa Agropecuária Brasileira, 33(1):7786.

Smiderle, O.J.; Gianluppi, D.; Gianluppi, V. 2004. Plantio Direto: Roraima em busca de eficiência. A Granja, (665):87-89.

Smiley, R.W.; Ogg, A.G.; Cook, R.J. 1992. Influence of glyphosate on Rhizoctonia root ort, growth and yeld of barley. Plant Disease, 76(9):937-942. 
Smit, E.; Leeflang, P.; Gommans, S.; Van Den Broek, J.; Van, M.S.; Wernars, K. 2001. Diversity and seasonal fluctuations of the dominant members of the bacterial soil community in a wheat field as determined by cultivation and molecular methods. Applied and Environmental Microbiology, 67(5):2284-2291.

Spadotto, C.A. Uso de herbicidas no Brasil. Comitê de Meio Ambiente, Sociedade Brasileira da Ciência das Plantas Daninhas. Disponível em: <http//www.cnpma.embrapa.br/herbicidas $>$. Acesso em 20 junho de 2002.

Sparling, G.P.; Hart, P.B.S.; August, J. A.; Leslie, D.M. 1994. A comparison of soil and microbial carbon, nitrogen, and phosphorus contents, and macro-aggregate stability of a soil under native forest and after clearance for pastures and plantation forest. Biology and Fertility of Soils, 17(1): 91-100.

Valverde, A.; Velazquez, E.; Gutierrez, C.; Cervantes, E.; Ventosa, A.; Igual, J. M. 2003. Herbaspirillum lusitanum sp. nov., a novel nitrogen-fixing bacterium associated with root nodules of Phaseolus vulgaris. International Journal of Systematic and Evolutionary Microbiology, 53(6):1979-1983.

Van Elsas, J.D.; Heijnen, C.E. 1990. Methods for the introduction of bacteria into soil : A review. Biology and Fertility of Soils, 10(1):127-133.

Vance, E.D.; Brookes, P.C.; Jenkinson, D.S. 1987. An extraction method for measuring soil microbial biomass C. Soil Biology and Biochemistry, 19(6):703-707.
Vance, E.D.; Nadkarni, N.M. 1990. Microbial biomass and activity in canopy organic matter and the forest floor of a tropical cloud forest. Soil Biology and Biochemistry, 22(5):677-684.

Villela, D.M. 1997. Matéria orgânica do solo em Roraima. In: Barbosa, R.I.; Ferreira, E.J.G.; Castellón, E. G. (Eds). Homem, ambiente e ecologia no estado de Roraima. . Instituto Nacional de Pesquisa da Amazônia (INPA). Manaus, Amazonas. p.381-399, 1997

Wachowska, U.; Banaszkiewicz, T. 1999. Effect of herbicide roundup on microrganisms in the rhizosphere of grasses. Natural Science, 2(2):191-200.

Wardle, D.A.; Parkinson, D. 1990. Influence of the herbicide glyphosate on soil microbial community structure. Plant and Soil, 122(1):29-37.

Xavier, G. R.; Silva, F.V.; Zilli, J.E.; Rumjanek, N.G. 2004. Adaptação de método para extração de DNA microbiano. Seropédica: EMBRAPA, 24p. (Embrapa Agrobiologia. Documentos, 171).

Recebido em 20/05/2005

Aceito em 26/02/2007 
